\title{
DOE/ MT/93009-1
}

\section{FINAL REPORT}

for

Department of Energy

Pittsburgh Energy Technology Center

on

\section{SIMULTANEOUS $\mathrm{SO}_{2}$ /NO SEPARATION FROM} FLUE GAS USING HFCLM

(Grant Number DE-FG22-93MT93009)

by

Dr. Keith Schimmel

Principal Investigator

Department of Chemical Engineering

North Carolina A\&T State University

Greensboro, NC 27411

U.S. DOE PATENT CLEARANCE NOT REQUIRED PRIOR TO PUBLICATION OF THIS REPORT

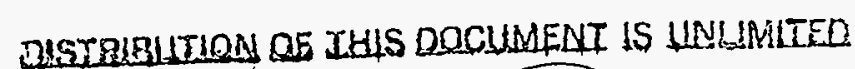
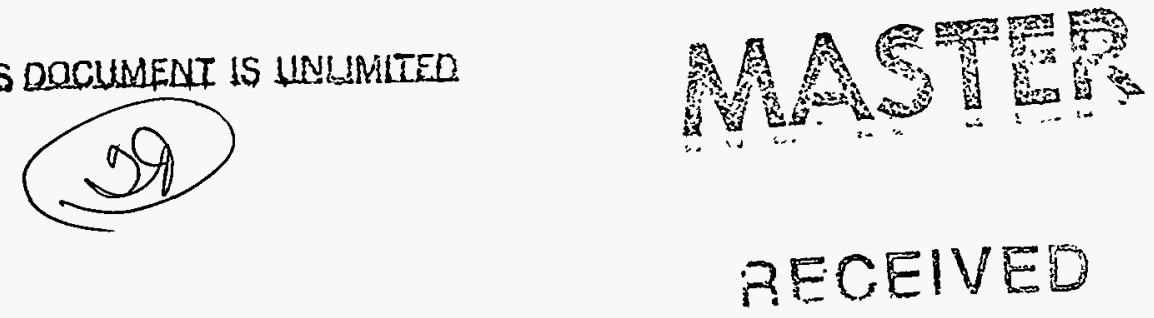

FEB $O 91995$

OSTI 


\section{DISCLAIMER}

This report was prepared as an account of work sponsored by an agency of the United States Government. Neither the United States Government nor any agency thereof, nor any of their employees, make any warranty, express or implied, or assumes any legal liability or responsibility for the accuracy, completeness, or usefulness of any information, apparatus, product, or process disclosed, or represents that its use would not infringe privately owned rights. Reference herein to any specific commercial product, process, or service by trade name, trademark, manufacturer, or otherwise does not necessarily constitute or imply its endorsement, recommendation, or favoring by the United States Government or any agency thereof. The views and opinions of authors expressed herein do not necessarily state or reflect those of the United States Government or any agency thereof. 


\section{DISCLAIMER}

Portions of this document may be illegible in electronic image products. Images are produced from the best available original document. 


\section{ABSTRACT}

Abatement technologies for oxides of sulfur and nitrogen present in flue and stack gases from coal fired boilers are becoming increasingly important. Scrubbing the gases with an aqueous limestone slurry to remove $\mathrm{SO}_{2}$ is a widely used treatment process. These scrubbing solutions are, however, not very effective in removing No. In addition, the process is expensive and produces large volumes of sludge.

The liquid membrane from a $0.01 \mathrm{M}$ aqueous solution of $\mathrm{Fe}^{2+}$ EDTA has been found to have a very high selectivity for No over $\mathrm{N}_{2}$. Thus, $\mathrm{SO}_{2} / \mathrm{NO}_{\mathrm{x}}$, identified as the source of acid rain, can be removed simultaneously using an aqueous $\mathrm{Fe}^{3+}$ EDTA solution in a hollow fiber contained liquid membrane (HFCLM) permeator with hydrophobic fibers (Mujamdar et al., 1992). The HFCLM configuration has addressed previous concerns about liquid membrane stability for an application such as this.

In this project, a flow apparatus was constructed that will allow simultaneous $\mathrm{SO}_{2} / \mathrm{NO}$ removal and recovery using two hollow fiber modules in series. Flowing the liquid membrane on the shell-side of the modules it is hypothesized will enhance the performance over that of HFCLMs without loss of stability. From the work completed in this exploratory project, it was concluded that to move the current state-of-the-art for this promising technology toward commercialization will require progress in the following areas: (1) sensitivity of the performance of the system to temperature changes, (2) validation of a mass transfer model to be used in scale-up calculations, (3) data on alternative flow 
schemes, and (4) overall process economics calculations. Partial funding to complete these tasks has been secured along with Christopher Haggins, a NACME Lincoln Hawkins Undergraduate Research Fellowship recipient who will be a chemical engineering senior next year. 


\section{TABLE OF CONTENTS}

$\begin{array}{lc}\text { TITLE PAGE } & \text { Page } \\ \text { ABSTRACT } & \text { i } \\ \text { TABLE OF CONTENTS } & \text { ii } \\ \text { PROJECT ACCOMPLISHMENTS } & \text { iv } \\ \text { INTRODUCTION } & 1 \\ \text { THEORETICAL WORR } & 3 \\ \text { EXPERIMENTAI WORK } & 7 \\ \text { CONCLUSIONS } & 18 \\ \text { FOTURE WORK } & 22 \\ \text { LITERATURE REFERENCES } & 23 \\ \text { APPENDIX: MaSS TISANSFEI MOdel FORTRAN COde } & 24\end{array}$




\section{PROJECT ACCOMPLISHMENTS}

Considerable work has been accomplished through this exploratory grant. Due to the complexity of the experimental setup necessary to safely perform the desired experiments, most of the tasks accomplished have been in the area of experimental setup design and development. Tasks completed in this area include:

1) Purchase and testing of a TOX ARRAY 1500 (MCNeil International) for measuring No concentrations in the range of 100 to $1,000 \mathrm{ppm}$.

2) Purchase and testing of CHROMOSIL 310 (Supelco, Inc.) GC packed columns for measuring $\mathrm{SO}_{2}$ concentrations in the range of 1,000 to $10,000 \mathrm{ppm}$.

3) Purchase of mass flow controllers and dynablender (Matheson) for control of feed composition and flow rate.

4) Purchase, construction, and testing of flow setup that includes compressed gases (air, $\mathrm{SO}_{2}, \mathrm{NO} / \mathrm{N}_{2}$, and $\mathrm{CO}_{2}$ ), stainless steel pressure vessels, pressure gages, flow controllers, teflon fittings and tubing, and two celgard hollow fiber membrane modules (Hoechst Celanese) for simultaneous extraction and recovery of $\mathrm{SO}_{2}$ and No. 
Toward the end of having the capability of theoretically predicting the behavior of the flow system, the FORTRAN code for the mass transfer model of Yun (1993) has been obtained, tested, and is being modified. Previously this code was for the transport of a single chemical species (copper) in a hollow fiber extraction module. The code is being modified to describe both the extraction and recovery of a single chemical species. Future work will extend this code to the multispecies case of simultaneous extraction and recovery of $\mathrm{SO}_{2}$ and $\mathrm{NO}$.

From the work completed in this exploratory project, it was concluded that to move the current state-of-the-art for this promising technology toward commercialization will require progress in the following areas: (1) sensitivity of the performance of the system to temperature changes, (2) validation of a mass transfer model to be used in scale-up calculations, (3) data on alternative flow schemes, and (4) overall process economics calculations. Partial funding to complete these tasks has been secured along with Christopher Haggins, a NACME Iincoln Hawkins Undergraduate Research Fellowship recipient who will be a chemical engineering senior next year. Additional funding to complete these tasks is currently being sought from EPA and DOE. 


\section{INTRODUCTION}

Advanced separation technologies are being developed to effect $\mathrm{SO}_{2}$-NO removal from flue gas (Walker et al., 1985), improve separation efficiency, and reduce the treatment cost. Membrane gas separation is one of the technologies under development. Membrane processes are simple, often less expensive, and are modular in nature for ease of scale-up or flexibility. Polymeric membranes, however, do not currently exhibit the required combination of high flux and selectivity.

Iiquid membranes may be, therefore, better candidates, since diffusivities of gaseous species through liquids are orders of magnitude larger than those through polymeric solids. Furthermore, facilitating agents can be added to liquid membranes to enhance the flux of certain species significantly while generating high selectivity between the permeants of interest (here $\mathrm{SO}_{2}$ and $\mathrm{NO}$, and the other species $\left(\mathrm{CO}_{2}, \mathrm{O}_{2}\right.$, and $\left.\mathrm{N}_{2}\right)$. In addition, the membrane process not only removes $\mathrm{SO}_{2}$ and No from the flue gas, but also can concentrate simultaneously these species in the product side for easier disposal and/or possible further use.

Liquid membranes have been studied in immobilized Iiquid membrane (IIM) form for gas separations (Ward and Robb, 1967; otto and Quinn, 1971; Suchdeo and Schultz, 1974; Matson et al., 1977; Kimura and Walmet, 1980; Bhave and Sirkar, 1986; Hughes et 
al., 1986; Meldon et al., 1986). The first study on $\mathrm{SO}_{2}$ separation via an ILM was carried out by Ward and Neulander (1970). ILMs are generally stable, but they have short operating lives and can not be regenerated in situ (Kimura and Walmet, 1980; Matson et al., 1983; Sengupta and Sirkar, 1986) .. A different liquid membrane structure called the Hollow Fiber Contained Liquid Membrane (HFCLM) has been used recently for liquid separations (Sengupta et al., 1988a, 1988b; Basu and Sirkar, 1991) and for separation of gas mixtures (Majumdar et al., 1988, 1989; Guha et al., 1991, 1992); it eliminates most of the deficiencies of the traditional ILM. The lumen of the hollow fibers carries the feed and strip solutions under proper pressure conditions. Guha et al. (1992) have demonstrated that the HFCLM system can be operated successfully in different modes: sweep gas, sweep liquid, permeate side vacuum, and conventional permeation.

Sengupta et al. (1990) have studied the permeation behavior of $\mathrm{SO}_{2}, \mathrm{CO}_{2}, \mathrm{O}_{2}$, and $\mathrm{N}_{2}$ present in a typical flue gas through various liquid membranes. Excellent permeabilities of $\mathrm{SO}_{2}$ and very high selectivities between $\mathrm{SO}_{2}-\mathrm{CO}_{2}(50-250)$ and $\mathrm{SO}_{2}-\mathrm{N}_{2}(1500-$ 3500) were obtained using pure water and facilitated transport with aqueous solutions of various inorganic salts, e.g., $\mathrm{NaHSO}_{3}$, $\mathrm{Na}_{2} \mathrm{SO}_{3}, \mathrm{Fe}^{2+} \mathrm{EDTA}$, and $\mathrm{Fe}^{3+} \mathrm{EDTA}$, and with $\mathrm{SO}_{2}$ concentrations in the range 500 to $5000 \mathrm{ppm}$. These values are considerably higher than the polymeric membrane selectivities $\left(\mathrm{SO}_{2}-\mathrm{CO}_{2}\right.$ selectivity of 10 and $\mathrm{SO}_{2}-\mathrm{N}_{2}$ selectivity of 250 ) obtained by Baker et al. (1988). 
In facilitated transport permeation-separation of a gas species (permeant) from a gas mixture, the liquid membrane contains a nonvolatile carrier that reacts reversibly with the particular species. Any free species in the liquid membrane diffuse across the membrane; simultaneously the carrier-permeant complex formed at the feed/membrane interface diffuses through the membrane and dissociates into the carrier and the permeant at the sweep/membrane interface. Simultaneous diffusion of the free permeant species and the permeant-carrier complex enhances the total mass flux of the permeant. Such systems, although complex, have been analyzed for ILMs by solving the reaction-diffusion equations in one dimension along the film (Majumdar et al., 1992). For pure water membranes, the following principal ionization reaction occurs with $\mathrm{SO}_{2}$ (Roberts and Friedlander, 1980):

$$
\mathrm{SO}_{2}+2 \mathrm{H}_{2} \mathrm{O} \rightarrow \mathrm{HSO}_{3}^{-}+\mathrm{H}_{3} \mathrm{O}^{+}
$$

On the other hand the permeation of No through an aqueous solution of $\mathrm{Fe}^{3+}$ EDTA is facilitated by the complex formed by the reaction:

$$
N O+F e^{3+} E D T A-F e^{3+E D T A . N O}
$$

The Iiquid membrane from a $0.01 \mathrm{M}$ aqueous solution of $\mathrm{Fe}^{3+} \mathrm{EDTA}$ has been found to have a very high selectivity for No over $\mathrm{N}_{2}$. Thus $\mathrm{SO}_{2} / \mathrm{NO}_{\mathrm{x}}$, identified as the source of acid rain, can be removed simultaneously using an aqueous $F e^{3+}$ EDTA solution in a 
HFCLM permeator with hydrophobic fibers (Mujamdar et al., 1992). Majumdar et al. (1994) have carried out HFCLM separation studies at $25^{\circ} \mathrm{C}$ to remove $\mathrm{SO}_{2}$ from a mixture of $\mathrm{SO}_{2}-\mathrm{CO}_{2}-\mathrm{O}_{2}-\mathrm{N}_{2}$ using water and $1 \mathrm{~N} \mathrm{NaHSO}_{3}$ liquid membranes operating in the sweep and vacuum modes. They report $\mathrm{SO}^{2}$ removal of $60-95 \%$ from a feed of $5000 \mathrm{ppm}$ $\mathrm{SO}_{2}$. Majumdar et al. (1994) have also performed HFCLM studies to eliminate $\mathrm{SO}_{2}$ and $\mathrm{NO}$ simultaneously from a mixture of $\mathrm{SO}_{2}-\mathrm{NO}-\mathrm{CO}_{2}-$ $\mathrm{O}_{2}-\mathrm{N}_{2}$ using $0.01 \mathrm{M} \mathrm{Fe} e^{2+} \mathrm{EDTA}$ at $24^{\circ} \mathrm{C}$ and $70^{\circ} \mathrm{C}$ and $0.01 \mathrm{M} \mathrm{Fe}{ }^{3+} \mathrm{EDTA}$ at $70^{\circ} \mathrm{C}$. They report $70-90 \%$ removal of $\mathrm{SO}_{2}$ and $50-70 \%$ removal of No with little performance difference between the high and low temperatures.

In this exploratory research project, the removal and recovery of $\mathrm{SO}_{2}$ and $\mathrm{NO}$ from gas containing $\mathrm{O}_{2}, \mathrm{~N}_{2}$, and $\mathrm{CO}_{2}$ was explored using $0.01 \mathrm{M} \mathrm{Fe}^{3+} \mathrm{EDTA}$ liquid membrane in two hollow fiber membrane permeators in series using the sweep operating mode. The novel concept of using a mobile liquid membrane to improve the performance is explored. 


\section{THEORETICAL WORK}

The contained liquid membrane in the shell side of a HFCLM permeator operated in either the sweep or vacuum modes is generally stationary except for any movement caused by membrane liquid replenishment. Unlike ILM, a HFCLM configuration offers the additional possibility of operating a module with the liquid membrane in uniform motion; the liquid exiting from one end of the permeator may be recirculated to the other end of the shell side of the permeator. The movement of the liquid membrane should be beneficial in systems such as the one to be explored in this study in which most of the mass transfer resistance lies in the membrane liquid. Such a liquid membrane may be identified as a mobile liquid membrane (MLM). The behavior of such a hollowfiber contained mobile liquid membrane has not been previously studied (Majumdar et al., 1992). Because HFCLM modules are no longer commercially available, the desired phenomenon will be studied using two hollow fiber modules in series.

The modeling of transport in hollow fiber membrane modules is complex for a variety of reasons. For example, the analyte concentrations in the feed, strip, and membrane phases vary along the permeator length. The mass transfer patterns are not uniform due to the cylindrical geometry of the fiber surface. Further, there are uncertainties regarding the effect of analyte concentration on its distribution coefficient, the true diffusion inside the tortuous pores, and the two dimensional effects as the 
analyte diffuses from the bulk into the pores and vice versa. Majumdar et al. (1993) have provided theoretical first order estimates of the rate of mass transfer in HFCLM permeators by assuming that the overall mass transfer resistance can be expressed as the sum of individual resistances in series. In general, the transfer resistances of the microporous hollow fiber walls are practically negligible. The substrate transfer coefficients are typically an order of magnitude higher than the liquid membrane transfer coefficients. Further, if feed and sweep (or permeate, for vacuum runs) flow rates are known, one can estimate the film transfer coefficients using average correlations and overall mass transfer coefficients may be calculated from the available experimental data (pressures, flow rates, and compositions).

Yun et al. (1993) have presented a model for the extraction of copper from an aqueous stream with a chemical reaction occurring in the liquid membrane. This model is presented below and is being modified to predict both the removal and recovery of copper. This model will then be further modified to describe the removal and recovery of $\mathrm{SO}_{2}$ and No in a gas containing oxygen, carbon dioxide, and nitrogen.

\section{A. Mathematical Model}

In solvent extraction, a commonly used industrial process, a solute in a solution (aqueous or organic) is extracted into an 
immiscible solvent (aqueous or organic) by dispersing one of the immiscible phases as drops in the other phase. Thus, a large interfacial area is created, and the extraction rate is increased. After the extraction is completed, the phases are separated and the dispersed phase is coalesced (Prasad et al., 1992).

Membrane-based solvent extraction devices were recently developed. In such devices, extraction was accomplished without dispersing one phase as drops in another phase, and coalescence is not essential. The flow rates of both phases (aqueous and organic) were varied over wide ranges without flooding as long as appropriate pressure conditions were maintained (Prasad et al., 1992).

Microporous membranes may be in each of the following forms: symmetric, asymmetric, and composite, and their pore sizes may be evenly or unevenly distributed. However, The theoretical aspect of membrane-based solvent extraction was developed primarily for thin, symmetric membranes with no variations in porosity and pore sizes across the membrane (Prasad et al., 1992).

For a hollow fiber microporous membrane configuration, the interfacial areas on the two sides of the hollow fiber are different. The overall mass transfer coefficients may be determined based on the surface area using either the inside or outside diameter of the hollow fiber. In order to calculate an overall mass transfer coefficient, the interfacial area must be based on the diameter where the aqueous-organic phase interface 
is located (Prasad et al., 1992).

The steps in the extraction process of copper are as follows (Yun, 1993):

1) The copper ion in the aqueous phase (tube-side) diffuses from the bulk to the aqueous-organic interface (inside wall of tube) through the boundary layer.

2) At the aqueous-organic interface, one mole of copper ion in the aqueous phase reacts with two moles of free oxime (active component) in the organic phase filled in the membrane pore to form copper-oxime complex by interchanging with two moles of hydrogen ion of free oxime. Next, the hydrogen ion interchanged with copper ion is released into the boundary layer of the aqueous phase. The hydrogen ion diffuses to the bulk of the aqueous phase.

3) Copper-oxime complex moves from the aqueous-organic interface to the outside wall of tube through the microporous hydrophobic membrane pore by diffusion and free oxime diffuses in the opposite direction from shell-side into the pore.

4) Copper-oxime complex diffuses from outside wall of the tube to the bulk of the organic phase (shell-side) which is flowing countercurrently to the aqueous phase (tube-side).

The reaction occurring in the liquid membrane may be represented as follows:

$$
M(a q)+2 O(o r g)=C(o r g)+2 H(a q)
$$

where $\mathrm{M}=$ copper ion in aqueous phase, $\mathrm{Cu}^{2+} ; \mathrm{H}=$ hydrogen ion in aqueous phase, $\mathrm{H}^{+} ; \mathrm{O}=$ free oxime in organic phase, $\mathrm{RH}$ (org); and $\mathrm{C}=$ copper-oxime complex in organic phase, $\mathrm{R}_{2} \mathrm{Cu}$ (org). The equilibrium constant of equation (2.1) may be expressed as follows: 


$$
K_{e q}=\frac{\left[R_{2} C u(o r g)\right]\left[H^{*}(a q)\right]^{2}}{[R H(o r g)]^{2}\left[C u^{2 *}(a q)\right]}
$$

or

$$
K_{e q}=\frac{[C(o r g)][H(a q)]^{2}}{[o(o r g)]^{2}[M(a q)]}
$$

\section{B. Governing Equations}

Regions along the radial direction of a hollow fiber are defined as follows:

$$
\begin{array}{ll}
t= & \text { tube-side, } \\
t m=\text { the boundary between the tube inside and the } \\
\text { membrane substrate at } r=R_{i}, \\
\mathrm{~m}=\text { the membrane substrate, } \\
\text { sm }=\text { the boundary between the membrane substrate } \\
\text { and }
\end{array}
$$

Regions along the axial direction are defined by

$$
\begin{aligned}
& z=0: \text { the tube-side inlet or the shell-side outlet, } \\
& z=L: \text { the tube-side outlet or the shell-side inlet. }
\end{aligned}
$$

The supersript '-' on the chemical species refers to the axial position at $z=z-\Delta z$. 
1. Chemical reaction for copper extraction

The rate of transfer of copper by interfacial chemical reaction in the module segment of length $\Delta \mathrm{Z}$ consisting of $\mathrm{N}_{f}$ fibers is given by $\left(-J^{R}\right)$ :

$$
J^{R_{-}}\left(2 \pi R_{1} \Delta z N_{f}\right) k_{\mathrm{e}}\left[\frac{C_{t m} H_{t m}}{K_{e q} O_{t m}}-\frac{M_{t m} O_{t m}}{H_{t m}}\right]
$$

2. Shell-side

free oxime:

$$
J_{0}^{s}=\left(2 \pi R_{0} \Delta z N_{f}\right) k_{0}^{s}\left(O_{s}-O_{s m}\right)
$$

$$
J_{0}^{s}-Q_{s}\left(O_{s}-O_{s}^{-}\right)
$$

complex:

$$
\begin{gathered}
J_{c}^{s}-\left(2 \pi R_{0} \Delta z N_{f}\right) k_{c}^{s}\left(O_{s}-O_{s m}\right) \\
J_{c}^{s}-Q_{s}\left(C_{s}-C_{s}^{-}\right)
\end{gathered}
$$

3. Membrane substrate

free oxime: 


$$
J_{0}^{m}=\left(2 \pi R_{I m} \Delta z N_{f}\right) k_{0}^{m}\left(O_{s m}-O_{t m}\right)
$$

complex:

$$
J_{c}^{m}=\left(2 \pi R_{1 m} \Delta z N_{f}\right) k_{c}^{m}\left(C_{s m}-C_{t m}\right)
$$

4. Tube-side

copper ion:

$$
J_{M}^{t}-\left(2 \pi R_{1} \Delta z N_{f}\right) k_{m}^{t}\left(M_{t m}-M_{t}\right)
$$

$$
J_{M}^{t}=Q_{t}\left(M_{t}-M_{t}^{-}\right)
$$

hydrogen ion:

$$
J_{H}^{t}=\left(2 \Pi R_{i} \Delta z N_{f}\right) k_{H}^{t}\left(H_{t m}-H_{t}\right)
$$

$$
J_{H}^{t}-Q_{t}\left(H_{t}^{-H_{t}^{-}}\right)
$$

The eleven equations (equation (2.4)-equation (2.14)) contain the following eleven variables: $J, M_{t}, M_{t m}, H_{t}, H_{t m}, O_{s}$, $\mathrm{O}_{s m}, \mathrm{O}_{\mathrm{tm}}, \mathrm{C}_{s}, \mathrm{C}_{\mathrm{sm}}$, and $\mathrm{C}_{\mathrm{tm}}$. From equation $(2.5)-(2.14), \mathrm{M}_{\mathrm{tm}}, \mathrm{O}_{\mathrm{tm}}, \mathrm{H}_{\mathrm{tm}}$, and $C_{t m}$ can be expressed by one variable, $J$,

$$
2 J-2 J^{R}-2 J_{C}^{s}-2 J_{C}^{m}-2 J_{H}^{t}--J_{0}^{s}-J_{0}^{m}-J_{B}^{t}
$$


since $\mathrm{O}_{s}^{-}, \mathrm{C}_{\mathrm{s}}^{-}, \mathrm{M}_{\mathrm{t}}^{-}$, and $\mathrm{H}_{\mathrm{t}}^{-}$are known from calculations in the previous cell. Therefore,

$$
\begin{aligned}
& O_{t m}-O_{s}^{-}\left(1+K_{8} J\right) \\
& C_{t m^{-}} C_{s}^{-}\left(1+K_{9} J\right) \\
& M_{t m}^{-}-M_{t}^{-}\left(1+K_{10} J\right) \\
& H_{t m}-H_{t}^{-}\left(1+K_{11} J\right)
\end{aligned}
$$

After substituting equations $(2.16)-(2.19)$ into equation (2.4), the following cubic equation in $J$ is obtained:

$$
J^{3}+a_{1} J^{2}+a_{2} J+a_{3}=0
$$

where the coefficients $a_{1}, a_{2}$, and $a_{3}$ are

$$
a_{3}=\frac{k_{12}+k_{13}}{k_{8} k_{11}+k_{9} k_{11}^{2} k_{12}+k_{8}^{2} k_{10} k_{13}}
$$




$$
\begin{gathered}
a_{1}=\frac{k_{8}+k_{11}+k_{11}^{2} k_{12}+k_{8}^{2} k_{13}+2 k_{9} k_{11} k_{12}+2 k_{9} k_{10} k_{13}}{k_{8} k_{11}+k_{9} k_{11}^{2} k_{12}+k_{8}^{2} k_{10} k_{13}} \\
a_{2}=\frac{1+k_{9} k_{12}+k_{10} k_{13}+2 k_{11} k_{12}+2 k_{8} k_{13}}{k_{8} k_{11}+k_{9} k_{1}^{2} k_{12}+k_{8}^{2} k_{10} k_{13}}
\end{gathered}
$$

and constants $k_{1}$ to $k_{13}$ are given by

$$
\begin{aligned}
& k_{1}=\left(2 \Pi R_{f} \Delta z N_{f}\right) k_{e} \\
& k_{2}=\left(2 \pi R_{o} \Delta z N_{f}\right) k_{o}^{s} \\
& k_{3}=\left(2 \pi R_{o} \Delta z N_{f}\right) k_{c}^{s} \\
& k_{4}=\left(2 \Pi R_{1 m} \Delta z N_{f}\right) k_{o}^{m} \\
& k_{5}=\left(2 \Pi R_{1 m} \Delta z N_{f}\right) k_{c}^{m} \\
& k_{6}=\left(2 \Pi R_{1} \Delta z N_{f}\right) k_{H}^{t} \\
& k_{7}=\left(2 \Pi R_{1} \Delta z N_{f}\right) k_{H}^{t} \\
& k_{8}=\frac{-2}{O_{s}^{-}}\left(\frac{1}{Q_{s}}-\frac{1}{k_{2}}-\frac{1}{k_{4}}\right)
\end{aligned}
$$




$$
\begin{gathered}
k_{9}-\frac{1}{C_{s}^{-}}\left(\frac{1}{Q_{s}}-\frac{1}{k_{3}}-\frac{1}{k_{5}}\right) \\
k_{10}=\frac{1}{M_{t}^{-}}\left(\frac{1}{Q_{t}}+\frac{1}{k_{6}}\right) \\
k_{11}=\frac{-2}{H_{t}^{-}}\left(\frac{1}{Q_{t}}+\frac{1}{k_{7}}\right) \\
k_{12}=\frac{-k_{1} C_{s}^{-} H_{t}^{-}}{K_{e q} O_{s}^{-}} \\
k_{13}=\frac{k_{1} O_{s}^{-} M_{t}^{-}}{H_{t}^{-}}
\end{gathered}
$$

From equations $(2.4),(2.7),(2.10)$, and $(2.11), \mathrm{J}$ can be expressed by

$$
-J-\left(2 \Pi R_{1} \Delta z N_{f}\right) K_{0}\left[M_{t}-\left(\frac{c_{s}}{K_{e q} \alpha^{2}}\right)\right]
$$

where $\alpha=\mathrm{O}_{\mathrm{tm}} / \mathrm{H}_{\mathrm{tm}}$, and

Total Resistance $=$ Reaction Resistance + Shell-side Resistance + Membrane Resistance + Tube-side Resistance

$$
\frac{1}{K_{0}}-\frac{1}{\alpha} \frac{1}{k_{e}}+\frac{R_{1}}{R_{0}} \frac{1}{K_{e q} \alpha^{2}} \frac{1}{k_{c}^{s}}+\frac{R_{1}}{R_{1 m}} \frac{1}{K_{e q} \alpha^{2}} \frac{1}{k_{c}^{m}}+\frac{1}{k_{M}^{t}}
$$




\section{c. Calculation Algorithm}

The FORTRAN code for a program to perform the mass transfer calculations is provided in Appendix A. The major steps involved in this calculation are outlined as follows:

1) Assume $M_{t}^{\text {out }}$ and set $\left.M_{t}^{\text {out }}\right|_{\text {old }}=M_{t}^{\text {out }}$.

2) Calculate $C_{s}$ out by total mass balance at steady state:

$Q_{t}\left(M_{t}^{\text {in }}-\left.M_{t}^{\text {out }}\right|_{\text {old }}\right)=Q_{t} C_{s}^{\text {out }}$, if there is no complex in the organic inlet stream.

3) Calculate $O_{s}^{\text {out }}$ by total oxime molar balnce at steady state: $O_{s}^{\text {out }}+C_{s}^{\text {out }}=O_{s}^{\text {in }}$.

4) Set $\mathrm{M}_{\mathrm{t}}=\mathrm{M}_{\mathrm{t}}^{\text {in }}, \mathrm{H}_{\mathrm{t}}=\mathrm{H}_{\mathrm{t}}{ }^{\text {in }}, \mathrm{C}_{\mathrm{s}}=\mathrm{C}_{\mathrm{s}}^{\text {out }}$, and $\mathrm{O}_{\mathrm{s}}=\mathrm{O}_{\mathrm{s}}^{\text {out }}$ at $\mathrm{z}=0$.

5) Calculate $J$ at $z=z+\Delta z$ from equation (2.20) and choose the correct $\mathrm{J}$.

6) Calculate other variables from equations (2.5)-(2.14). Repeat steps 5 and 6 up to $z=L$.

7) Set $\left.M_{t}^{\text {out }}\right|_{\text {new }}=M_{t}^{\text {out }}$ calculated at $z=L$.

8) Compare $\left.M_{t}^{\text {out }}\right|_{\text {new }}$ and $\left.M_{t}^{\text {out }}\right|_{\text {old }}$. If $\left|M_{t}^{\text {out }}\right|_{\text {old }}-\left.M_{t}^{\text {out }}\right|_{\text {new }} \mid>$ allowable error, set $\left.\mathrm{M}_{\mathrm{t}}^{\text {out }}\right|_{\text {old }}=\left.\mathrm{M}_{\mathrm{t}}{ }^{\text {out }}\right|_{\text {new }}$ and go back to step 2 ; if not stop the calculation and get the results. 


\section{EXPERIMENTAL WORK}

The permeator modules to be used in these experiments are prefabricated (Liqui-Cel Hoechst Celanese \#5PCM-106) and utilize Celgard X-10 microporous hydrophobic polypropylene hollow fibers (Hoechst-Celanese, Charlotte, NC). The experiments consist of removing $\mathrm{SO}_{2}$ and $\mathrm{NO}$ from a gas stream containing carbon dioxide, oxygen, and nitrogen using two microporous hydrophobic hollow fiber modules in series. The first module allowed the extraction to take place, and the second module allowed the back extraction to take place. The modules were manufactured by Hoechst celanese Corporation, and their specifications are listed in Table 3.1. Both the feed and strip stream were in a closed loop. The flow rates, temperature, feed concentration, liquid membrane composition, and differential pressures were the major experimental variables. The gas phase was maintained at a pressure lower than the aqueous phase pressure in order to keep the reaction interface at the outside wall of the lumen since the membrane was hydrophobic.

The experimental setup is shown in Figure 3.1. The setup consists of three segments: a waste gas side, a liquid membrane loop, and a permeate gas side. The waste gas side segment is located in the top portion of Figure 3.1 starting at the extractor and above. The liquid membrane loop is located between the extractor and back extractor. The permeate gas side starts at the back extractor and below. 
Table 3.1: Characteristics of hollow fiber modules

\begin{tabular}{|c|c|c|c|}
\hline $\begin{array}{l}\text { Fiber } \\
\text { Specs. }\end{array}$ & & $\begin{array}{l}\text { Module } \\
\text { specs. }\end{array}$ & \\
\hline Type & $\begin{array}{l}\text { Celgard } \mathrm{X} \text { - } \\
\text { I0 } \\
\text { microporous } \\
\text { polypropyle } \\
\text { ne }\end{array}$ & Material & Polypropylene \\
\hline $\begin{array}{l}\text { Number of } \\
\text { fibers }\end{array}$ & 2100 & Diameter & $2.5 \mathrm{~cm}$ \\
\hline $\begin{array}{l}\text { Internal } \\
\text { diameter }\end{array}$ & $240 \mu \mathrm{m}$ & Length & $20 \mathrm{~cm}$ \\
\hline $\begin{array}{l}\text { Wall } \\
\text { thickness }\end{array}$ & $30 \mu \mathrm{m}$ & $\begin{array}{l}\text { Overall } \\
\text { length } \\
\text { (incl. } \\
\text { endcaps) }\end{array}$ & $30 \mathrm{~cm}$ \\
\hline $\begin{array}{l}\text { Effective } \\
\text { pore size }\end{array}$ & $0.05 \mu \mathrm{m}$ & $\begin{array}{l}\text { effective } \\
\text { surface } \\
\text { area }\end{array}$ & $0.23 \mathrm{~m}^{2}$ \\
\hline porosity & $30 \%$ & $\begin{array}{l}\text { Effective } \\
\text { area/volume }\end{array}$ & $40 \mathrm{~cm}^{2} / \mathrm{cm}^{3}$ \\
\hline $\begin{array}{l}\text { Effective } \\
\text { fiber } \\
\text { length }\end{array}$ & $16 \mathrm{~cm}$ & $\begin{array}{l}\text { Priming } \\
\text { volume } \\
\text { (tubeside) }\end{array}$ & $19 \mathrm{~cm}^{3}$ \\
\hline $\begin{array}{l}\text { Potting } \\
\text { material }\end{array}$ & epoxy & $\begin{array}{l}\text { Priming } \\
\text { volume } \\
\text { (shellside) }\end{array}$ & $41 \mathrm{~cm}^{3}$ \\
\hline
\end{tabular}

The gases that make-up the waste gas stream are stored in three gas cylinders. In addition to these three gas cylinders, the waste gas stream also utilizes an air line. The first cylinder contains a mixture of $N O$ and $\mathrm{N}_{2}$. The second and third cylinders contain $\mathrm{SO}_{2}$ and $\mathrm{CO}_{2}$ respectively. The delivery pressure of the gas 


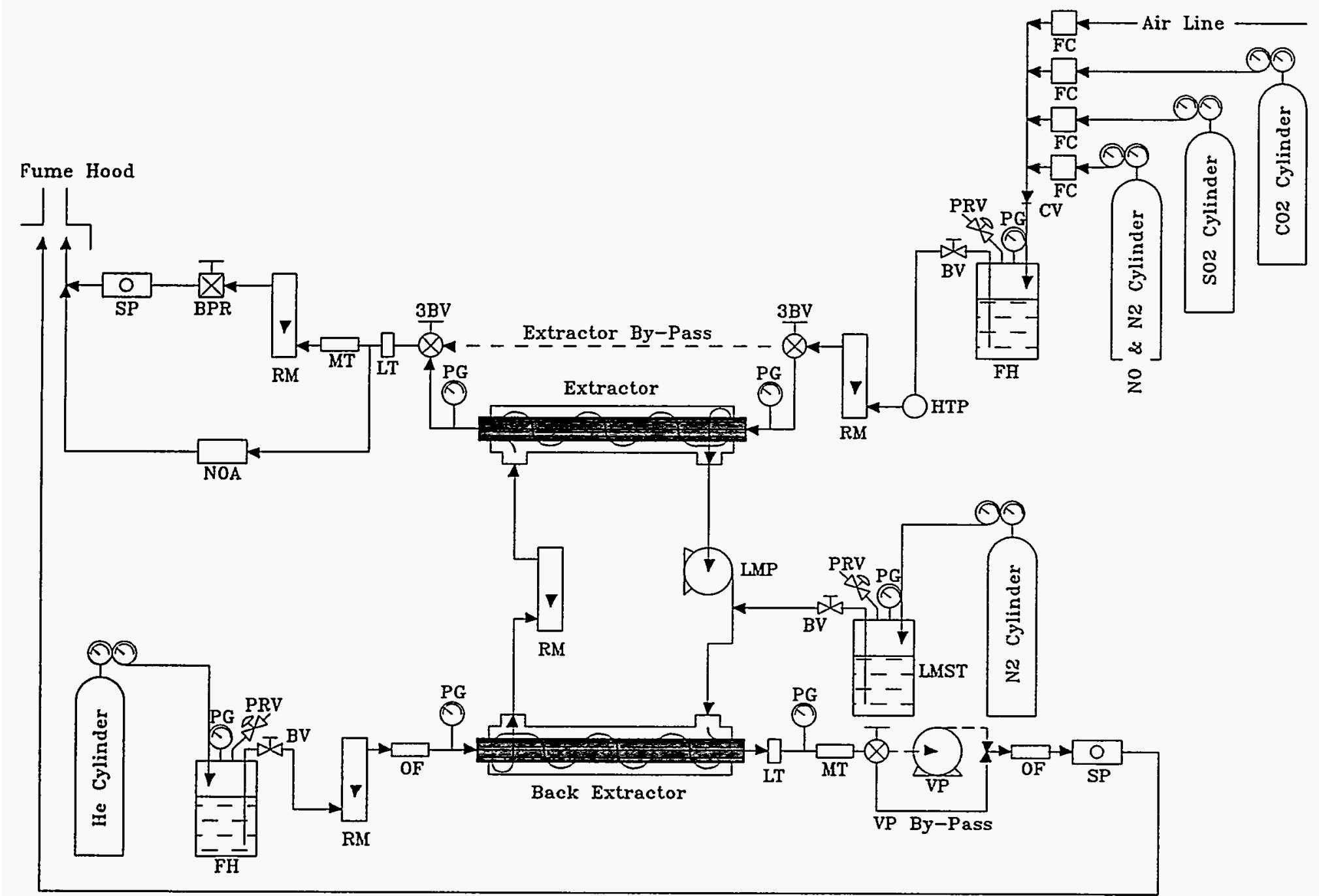

RM: Rotameter

OF: Oil Filter

BV: Ball Valve

SP: Sample Port

VP: Vacuum Pump

LIP: Liquid Membrane Pump

LIST: Liquid Membrane Stroage Tank

BPR: Back Pressure Regulator

LT: Liquid Trap

AIT: Moisture Trap

HTP: Humidity \& Temperature Probe

NOA: NO Analyzer

Flgure 3.I Experimental setup for gas separation using hollow fiber contained liquid membrane. 
from the cylinders and the air line are controlled by pressure regulators. The flow rate and blending of the gases in to the desired ratio is controlled by four Matheson flow controllers and a Matheson Multichannel Dyne Blender (Matheson Gas, Montgomeryville, $\mathrm{PA}$ ). After the waste gas stream is combined into one stream it is humidified in a feed humidifier(FH), a stainless steel pressure vessel. The $\mathrm{FH}$ is fitted with a pressure gauge (PG), pressure relief valve (PRV), and ball valve (BV). The humidity and temperature of the waste gas is measured by a humidity and temperature probe (HTP) after leaving the FH. The gas mixture then flows through a rotameter (RM) were the overall flow rate of the gas mixture is measured. The gas mixture then flows through a three-way ball valve (3BV) that allows the gas mixture to by-pass the extractor when needed. Before and after entering the extractor the pressure is measured by two pressure gauges (PG). The gas mixture passes through the tube side of the extractor. After exiting the extractor the purified waste stream passes through a three-way ball valve (connected to the previous 3BV), liquid trap (IT) and moisture trap (MT). Between the IT and MT a fraction of the gas stream is diverted to an in-line No analyzer (NOA). Then the flow rate is measured by a RM. Finally, the purified waste gas stream passes through a back pressure regulator (BPR), a sample port (SP), and then exits through a fume hood.

The liquid membrane is stored in the liquid membrane storage tank (IMST) that is equipped with the same equipment as the FH. The liquid membrane is forced into the extractor and back extractor 
by pressure supplied by a $\mathrm{N}_{2}$ gas cylinder. During operation the liquid membrane is circulated through the extractor and back extractor by the liquid membrane pump (IMP). The flow rate is measured by a RM. The pressure supplied by the $\mathrm{N}_{2}$ gas cylinder also forces more liquid membrane into the loop to replenish Iiquid membrane that is lost during operation.

The concentration of $\mathrm{SO}_{2}$ will be measured by a gas chromatograph. Samples of the waste gas side will be taken before and after processing by the extractor. Samples of the permeate gas side will be taken after the back extractor. The concentration of No will be measured by an in-line gas analyzer after the waste gas is processed by the extractor.

A major concern of this experiment was the determination of the feasibility of utilizing the existing gas chromatograph (GC), (Perkin Elmer \#8410). Several samples, which modeled the concentration levels of $\mathrm{SO}_{2}$ that would be present in the purified waste gas stream with $90 \% \mathrm{SO}_{2}$ removal, were injected into the GC. The existing GC accurately measured these samples in a reproducible manner. Furthermore, it was determined from this testing of the GC that it would also accurately measure concentrations of $\mathrm{SO}_{2}$ at sufficiently lower levels. Therefore, the existing $G C$ was determined to be capable of being utilized in this experiment. 


\section{CONCLUSIONS}

A flow apparatus for the study of $\mathrm{SO}_{2}$ and $\mathrm{NO}$ removal and recovery from flue gas has been successfully designed and constructed. The apparatus includes compressed gases (air, $\mathrm{SO}_{2}$, $\mathrm{NO} / \mathrm{N}_{2}$, and $\mathrm{CO}_{2}$ ), stainless steel pressure vessels, pressure gages, flow controllers, teflon fittings and tubing, and two celgard hollow fiber membrane modules (Hoechst Celanese) for simultaneous extraction and recovery of $\mathrm{SO}_{2}$ and NO.

Toward the end of having the capability of theoretically predicting the behavior of the flow system, the FORTRAN code for the mass transfer model of Yun (1993) has been successfully obtained and tested and is being modified. 


\section{FUTURE WORK}

The FORTRAN code of Yun (1993) is being modified to describe both the extraction and recovery of a single chemical species. Future work will extend this code to the multispecies case of simultaneous extraction and recovery of $\mathrm{SO}_{2}$ and $\mathrm{NO}$ in a gas containing carbon dioxide, oxygen, and nitrogen.

Experiments are currently being performed to gather data in the following areas: (1) sensitivity of the performance of the system to temperature changes, (2) validation of a mass transfer model to be used in scale-up calculations, (3) data on alternative flow schemes, and (4) overall process economics calculations. Partial funding to complete these tasks has been secured along with Christopher Haggins, a NACME Lincoln Hawkins Undergraduate Research Fellowship recipient who will be a chemical engineering senior next year. Additional funding to complete these tasks is currently being sought from EPA and DOE. 


\section{LITERATURE CITED}

Baker, R.W., Bell, C.M., Castro, R.C., Wijmans, J.G., Development of a Membrane $\mathrm{SO}_{\mathrm{x}} / \mathrm{NO}_{\mathrm{x}}$ Treatment system. Report for Contract No.: DE-AC22-87PC79856, Department of Energy, Pittsburgh, PA, 1988 .

Basu, R., Sirkar, K.K., Hollow Fiber Contained Liquid Membrane Separation of Citric Acid., AIChE J., 1991, 37, 383.

Bhave, R.R., Sirkar, K.K., Gas Permeation and Separation by Aqueous Membranes Immobilized Across the Whole Thickness or in a Thin Section of Hydrophobic Microporous Celgard Films. J. Membrane Sci, $1986,27,41$.

Drummond, C.J., Gyorke, D.F., Research Strategy for the Development of Flue Gas Treatment Technology, ACS Symp. Ser., 1986, 319, 146.

Guja, A.K., Studies on Different Gas Separation Modes with Hollow Fiper Contained Liquid Membrane, Ph.D Dissertation, stevens Institute of Technology, Hoboken, NJ, 1989.

Guja, A.K., Majumdar, S., Sirkar, K.K., A Larger-Scale study of Gas Separation by Hollow-Fiber-Contained Liquid Membrane Permeator., J. Membrane Sci, 1991, 62, 293. 
Guha, A.K., Majumdar, S., Sirkar, K.K., Gas separation Modes in a Hollow Fiber Contained Liquid Membrane Permeator, Ind. Eng. Chem Res., 1992, 31, 593.

Hughes, R.D., Mahoney, J.A., Steigelmann, E.F., Olefin Separation by Facilitated Transport Membranes. In Recent Developments in Separation Science, Li, N.N., Calo, J.M., Eds., CRC Press: Boca Raton, FL, 1986; Vol. 9, pg. 173.

Kimura, S.G., Walmet, G.F., Fuel Gas Purification with Permselective Membranes, Sep. Sci, Technology, 1989, 15, 1115.

Majumdar, S., A New Liquid Membrane Technique for Gas separation, Ph.D. Dissertation, Stevens Institute of Technology, Hoboken, NJ, 1986.

Majumdar, S., Guha, A.K., Sirkar, K.K., A New Iiquid Membrane Technique for Gas Separation, AIChE Journal, 1988, 34, 1135.

Majumar, S., Guha, A.K., Lee, Y.T., Sirkar, K.K., A Two Dimensional Analysis of Membrane Thickness in a Hollow Fiber Contained Liquid Membrane Permeator, J. Membrane Science, 1989, 43, 259. 
Majumdar, S., Sirkar, K.K., Sengupta, A., Hollow-Fiber Contained Iiquid Membrane. In Membrane Handbook; Winston Ho, W.S., Sirkar, K.K., Eds., Van Nostrand Reinhold: New York, NY 1992, Chapter 42, p. 764 .

Majumdar, S., Sengupta, A., Cha, J.S., Sirkar, K.K., simultaneous $\mathrm{SO}_{2} / \mathrm{NO}$ Separation from Flue Gas in a Contained Liquid Membrane Permeator, Ind. Eng. Chem. Res., 1994, 33(3), 667-675.

Matson, S.L., Herrick, C.S., Ward, W.J., Progress on the Selective Removal of $\mathrm{H}_{2} \mathrm{~S}$ from Gasified Coal Using an Immobilized Iiquid Membrane, Ind. Eng. Chem. Process Des. Dev., 1977, 16, 370 .

Matson, S.I., Lopez, J., Quinn, J.A., Separation of Gases with Synthetic Membranes, Chem. Eng. Sci. 1983, 38, 503.

Meldon, J.H., Paboojian, A., Rajangam, G., Selective $\mathrm{CO}_{2}$ Permeation in Immobilized Liquid Membranes, AIChE Symposium Ser., 1986, No. 248,114

otto, N.C., Quinn, J.A., The Facilitated Transport of Carbon Dioxide Through Bicarbonate Solutions, Chem. Eng. Sci., 1972, 26, 949 .

Roberts, D.I., Friedlander, S.K., Sulfur Dioxide Transport Across Aqueous Solutions: Part I, Theory, AIChE Journal, 1980, 26, 593. 
Sengupta, A., Sirkar, K.K., Membrane Gas Separation, In Progress in Filtration and Separation; Wakeman, R.J., Ed., Elsevier, Amsterdam, 1986; Vol. 4 , p. 289.

Sengupta, A., Basu, R., Sirkar, K.K., separation of solutes from Aqueous Solutions by Contained Iiquid Membranes, AIChE Journal, $1988 a, 34,1698$.

Sengupta, A., Basu, R., Prasad, R., sirkar, K.K., separation of Iiquid Solutions Contained Liquid Membranes, Sep. Sci, Technology, $1988 b, 23,1735$.

Sengupta, A., Raghuraman, B., Sirkar, K.K., Liquid Membranes for Flue Gas Desulfurization, J. Membrane Science, 1990, 51, 105.

Suchdeo, S.R., Schultz, J.S., The Permeability of Gases Through Reacting Solutions: The Carbon Dioxide-Bicarbonate Membrane System, Chemical Engineering Science, 1974, 29, 13.

Walker, R.J., Drummond, C.J., Ekmann, J.M., Evaluation of Advanced Separation Techniques for Applications to Flue Gas cleanup Processes for the Simultaneous Removal of sulfur Dioxide and Nitrogen oxides. Report DOE/PETC/TR-85/7, Department of Energy, Pittsburgh, PA, 1985. 
Ward, W.J., Robb, W.L., Carbon Dioxide-oxygen separation: Facilitated Transport of Carbon Dioxide Across a Liquid Film. Science, $1967,156,1481$.

Yun, C.-H., Removal of Pollutants and Recovery of Toxic Heavy Metals from Wastewater Using Microporous Hollow Fiber Modules. PhD Disseration, Stevens Institute of Technology, Hoboken, New Jersey, $1993,253 \mathrm{pp}$.

Yun, C.-H., Prasad, R., Guha, A., and Sirkar, K., "Hollow Fiber Solvent Extraction Removal of Toxic Heavy Metals from Aqueous Waste Streams," Ind. Eng, Chem. Res,, $32(6): 1186-1195,1993$. 


\section{APPENDIX: Mass Transfer Model Fortran Code}




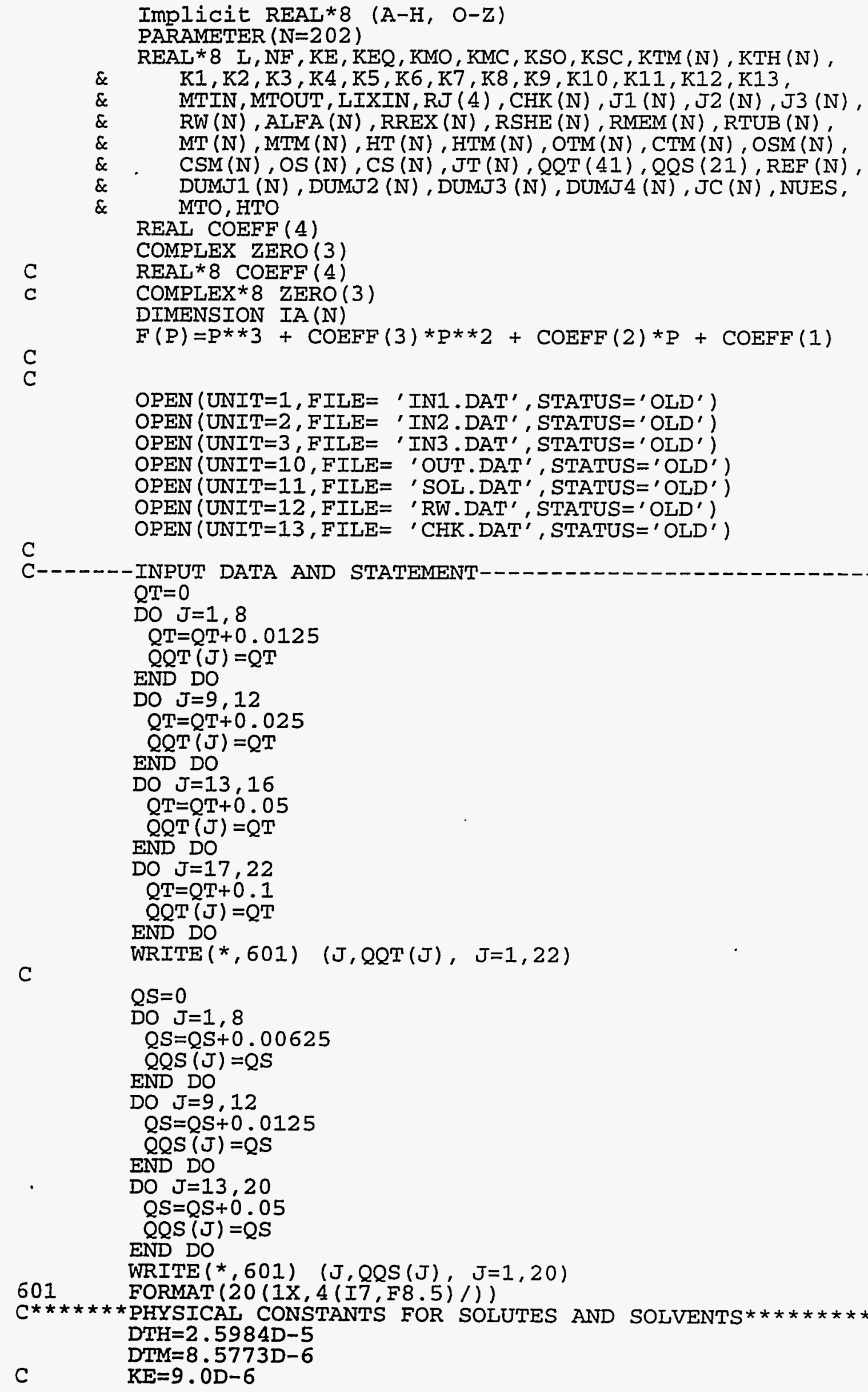


WRITE $(*, *)$ 'ENTER THE VALUE OF $\mathrm{KE}^{\prime}$

$\operatorname{READ}(*, *) \mathrm{KE}$

$\mathrm{KEQ}=1.7$

WRITE $(*, *)$ 'ENTER INLET COPPER CONCENTRATION, $\mathrm{mg} / \mathrm{L}$ '

$\operatorname{READ}(*, *)$ MTO

MTIN $=$ MTO $/ 63.55 / 1000 . / 1000$.

WRITE $(*, *)$ 'ENTER INLET pH'

$\operatorname{READ}(*, *)$ HTO

.HTIN $=10 . * *(-\mathrm{HTO}) / 1000$.

C******* CHARACTERISTICS OF SYSTEM $* *$

$\mathrm{PI}=3.141593$

$\mathrm{NF}=2100$

TAUM $=2.8$

$\mathrm{L}=16$.

$\mathrm{EM}=0.3$

$\mathrm{RI}=0.012$

$\mathrm{RO}=0.015$

RSI $=0.95$

$\mathrm{FI}=\mathrm{NF} *(\mathrm{RO} / \mathrm{RSI}) * * 2$

RLM $=(R O-R I) / D L O G(R O / R I)$

$\mathrm{C}$

$\mathrm{DH}=2 . *(\mathrm{RSI} * * 2 .-\mathrm{NF} * \mathrm{RO} * * 2) /.(\mathrm{RSI}+\mathrm{NF} * \mathrm{RO})$

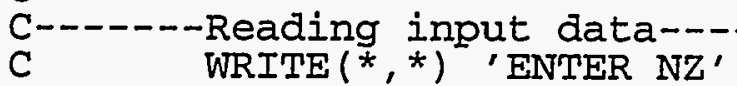

C $\quad \operatorname{READ}(*, *) \times \mathrm{XNZ}$

C NZ $=\mathrm{XNZ}$

$\mathrm{NZ}=100$

$\mathrm{NNZ}=\mathrm{FLOAT}(\mathrm{NZ}) / 5 .+0.1$

WRITE $(*, *)$ NZ, NNZ

C WRITE $(10,500) \mathrm{NZ}, \mathrm{NNZ}$

$500 \quad$ FORMAT (10X,' $\mathrm{NZ}=$ ', I4, $4 \mathrm{X},{ }^{\prime} \mathrm{NNZ}=$ ', I3)

C-..-

WRITE (*,*) 'IF YOU WANT TO USE OLD DATA OF LIX CONC.

\& FOR SHELI INLET ENTER 1, OTHERWISE 6'

READ $(*, 520)$ MC

520 FORMAT (I2)

IF (MC.EQ.1) GO TO 10

WRITE $(*, *)$ '1) IF $5.0 \mathrm{~V} / \mathrm{V}$ \% LIX - ENTER 1'

WRITE $(*, *), 2)$ IF 10.0 V/V क IIX - - ENTER 2'

WRITE $(*, *), 3)$ IF 20.0 V/V \& LIX -- ENTER 3,

$\operatorname{READ}(*, 520)$ ILIXV

IF (ILIXV.EQ.1) THEN

IIXIN $=5$

NUES $=0.8993$

$\mathrm{DSO}=1.0486 \mathrm{D}-5$

QS $=0.0209$

ELSE

IF (ILIXV.EQ.2) THEN

LIXIN $=10$

NUES $=0.9858$

$\mathrm{DSO}=9.7019 \mathrm{D}-6$

$\mathrm{QS}=0.0158$

$\mathrm{QT}=0.0698$

ELSE

IIXIN $=20$

NUES $=1.1968$

$\mathrm{DSO}=8.2144 \mathrm{D}-6$

. WRITE $(*, *)$ 'ENTER FLOW RATE OF ORGANIC SOLVENT, ml/sec' $\operatorname{READ}(*, *)$ QS

END IF

ENDIF

GO TO 20

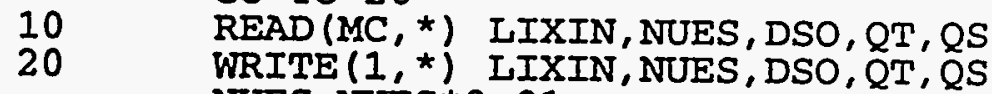

NUES $=$ NUES $* 0.01$

$\operatorname{LIXIN}=1.5596 *(\operatorname{IIXIN} / 100$. ) $/ 1000$. 


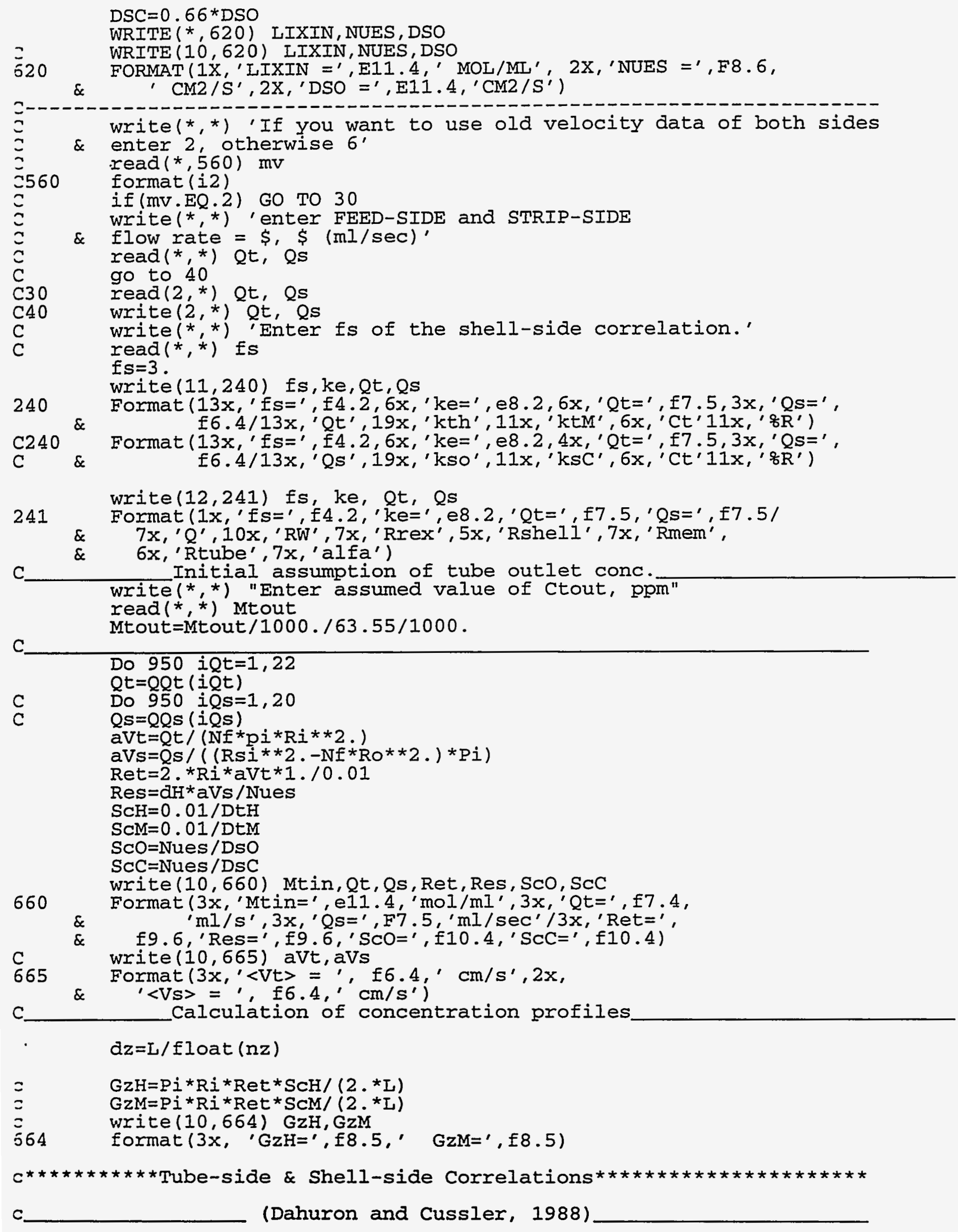




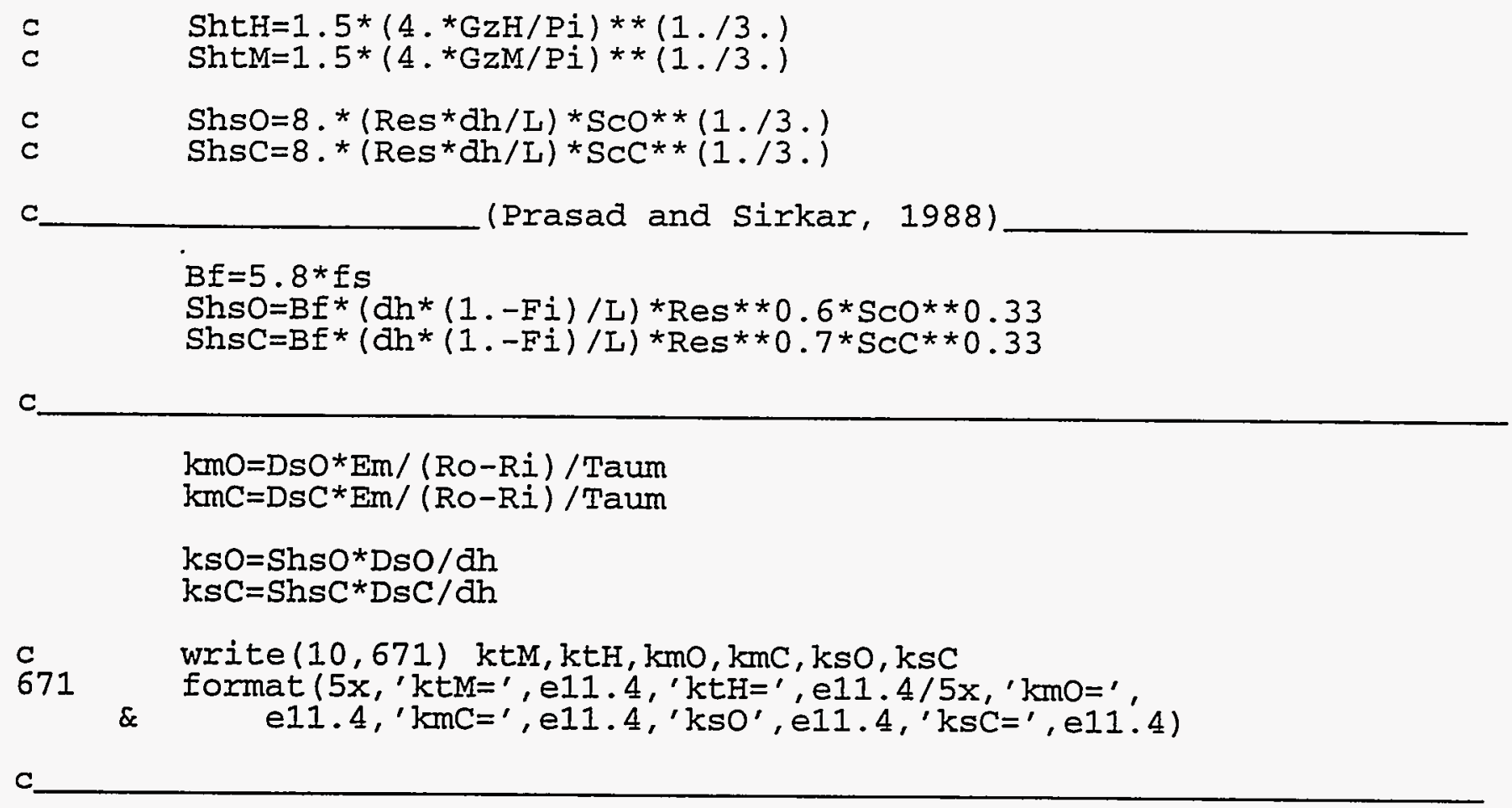

$\mathrm{k} 1=2 . * \mathrm{P} i * \mathrm{Ri} * \mathrm{dz}{ }^{*} \mathrm{~N} f * k e$

$\mathrm{k} 2=2 . * \mathrm{P} i * \mathrm{Ro}^{*} \mathrm{dz} * \mathrm{Nf} * \mathrm{ksO}$

$\mathrm{k} 3=2 . * \mathrm{Pi} * \mathrm{Ro} * \mathrm{dz} * \mathrm{Nf} * \mathrm{ksC}$

$\mathrm{k} 4=2 . * \mathrm{P} i * \mathrm{Rlm} \mathrm{m}^{*} \mathrm{dz} * \mathrm{Nf} * \mathrm{kmO}$

$k 5=2 . * P i * R I m * d z * N f * k m C$

Initial condition of both - side

C.

Mt (1) $=$ Mtin

Ht $(1)=$ Ht in

Osin=LIxin

Csin $=0$.

iter $=1$

c write $(13,702)$ Qt, Qs, LIXin

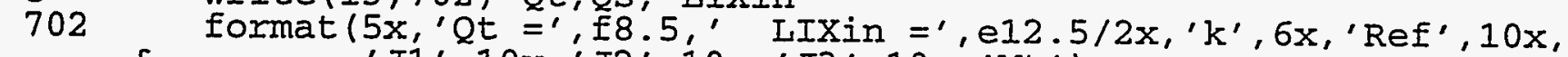
$\&$ ' J1', 10x, 'J2', 10x, 'J3', 10x, 'Mt')

90 continue

Cs $(1)=Q t *$ (Mtin-Mtout) /Qs

Os $(I)=\mathrm{LIXin}-2 \cdot{ }^{*} \mathrm{Cs}(1)$

iterlo $=1$

do $180 \mathrm{k}=2, \mathrm{nz}+1$

if(iterlo.EQ.1) then

$z k=(k-1) * d z$

sum $1 \mathrm{H}=0$.

$\operatorname{sum} 1 M=0$.

sum $2 \mathrm{H}=0$.

sum $2 M=0$.

do $m=1,20$

beta $=4 . *$ Float $(m-1)+8.13$.

$\mathrm{Cn}=1.01276 *$ beta** $(-1 . / 3$.

sum $1 \mathrm{H}=\operatorname{sum} 1 \mathrm{H}+\mathrm{Cn} * \operatorname{dexp}(-z \mathrm{z} *$ beta $* * 2 /(\mathrm{Ri} * \mathrm{Ret} * \mathrm{ScH}))$

$\operatorname{sum} 1 M=\operatorname{sum} 1 M+C n * \operatorname{dexp}(-z k *$ beta $* * 2 /(R i * \operatorname{Ret} *$ SCM $))$ 

end do $\operatorname{sum} 2 \mathrm{M}=\operatorname{sum} 2 \mathrm{M}+(\mathrm{Cn} /$ beta**2)*dexp $(-z \mathrm{k} *$ beta**2/(Ri*Ret*SCM$))$

write $(*, 112) k, Q t, \operatorname{sum} 1 \mathrm{H}, \operatorname{sum} 2 \mathrm{H}, \operatorname{sum} 1 \mathrm{M}, \operatorname{sum} 2 \mathrm{M}$

ShtF $=\operatorname{sum} 1 \mathrm{H} /\left(2 .{ }^{*} \operatorname{sum} 2 \mathrm{H}\right)$

ShtM $=\operatorname{sum} 1 \mathrm{M} /\left(2 .{ }^{*} \operatorname{sum} 2 \mathrm{M}\right)$

$\mathrm{GztH}=\mathrm{P} i * \mathrm{Ri} * \mathrm{Ret} * \mathrm{ScH} /(2 . * \mathrm{zk})$

GztM=Pi*Ri*Ret*SCM $/(2 . * z k)$

write(*,112) k, Qt, ShtH, ShtM, GztH, GztM

format ( $1 \mathrm{x}, \mathrm{i4}, \mathrm{f8} .5,4 \mathrm{e} 14.5$ )

$k t H(k)=S h t H * D t H /(2 . * R i)$

$\operatorname{ktM}(k)=\operatorname{ShtM} * \mathrm{DtM} /(2 . * \mathrm{R} i)$

diffH=dabs $(k t H(k)-k t H(k-1))$

diffM=dabs $(k t M(k)-k \operatorname{tM}(k-1))$

if (diffH.LE.1.0d-10.and.diffM.LE.1.0d-10) iterlo=2

else

$\mathrm{ktH}(\mathrm{k})=\mathrm{ktH}(\mathrm{k}-1)$

$\mathrm{ktM}(\mathrm{k})=\mathrm{ktM}(\mathrm{k}-1)$

end if

write $(*, 113) \mathrm{k}, Q t, \mathrm{ktH}(\mathrm{k}), \mathrm{ktm}(\mathrm{k})$

format ( $1 \mathrm{x}, \mathrm{i} 4, \mathrm{I8} .5,2 \pm 15.12)$

$k 6=2 . * P i * R i * d z * N f * k t M(k)$

$\mathrm{k} 7=2 . * \mathrm{P} i * \mathrm{Ri} * \mathrm{dz} * \mathrm{~N} f * \mathrm{ktH}(\mathrm{k})$

$\mathrm{k} 8=-2 \cdot *(1 \cdot / \mathrm{Qs}-1 \cdot / \mathrm{k} 2-1 \cdot / \mathrm{k} 4) / \mathrm{Os}(\mathrm{k}-1)$

$\mathrm{k} 9=(1 \cdot / \mathrm{Qs}-1 \cdot / \mathrm{k} 3-1 \cdot / \mathrm{k} 5) / \mathrm{Cs}(\mathrm{k}-1)$

$\mathrm{k} 10=(1 \cdot / \mathrm{Q} t+1 \cdot / \mathrm{k} \sigma) / \mathrm{Mt}(\mathrm{k}-1)$

$\mathrm{k} 11=-2 . *(1 . / \mathrm{Qt}+1 . / \mathrm{k} 7) / \mathrm{Ht}(\mathrm{k}-1)$

$\mathrm{k} 12=-\mathrm{k} 1 * \mathrm{Cs}(\mathrm{k}-1) * \mathrm{Ht}(\mathrm{k}-1) /(\mathrm{Keq} * \mathrm{Os}(\mathrm{k}-1))$

$\mathrm{k} 13=\mathrm{k} 1 * \mathrm{Mt}(\mathrm{k}-1) * \mathrm{Os}(\mathrm{k}-1) / \mathrm{Ht}(\mathrm{k}-1)$

$a 1=(k 8+k 11+k 12 * k 11 * * 2+k 13 * k 8 * * 2+2 . * k 9 * k 11 * k 12+2 . * k 8 * k 10 * k 13)$

$\&$ $/(\mathrm{k} 8 * \mathrm{k} 11+\mathrm{k} 9 * \mathrm{k} 12 * \mathrm{k} 11 * * 2+\mathrm{k} 10 * \mathrm{k} 13 * \mathrm{k} 8 * * 2)$

$\mathrm{a} 2=(1 .+\mathrm{k} 9 * \mathrm{k} 12+\mathrm{k} 10 * \mathrm{k} 13+2 . * \mathrm{k} 11 * \mathrm{k} 12+2 . * \mathrm{k} 8 * \mathrm{k} 13)$

$\&$

$/\left(\mathrm{k} 8 * \mathrm{k} 11+\mathrm{k} 9 * \mathrm{k} 12 * \mathrm{k} 11 * * 2+\mathrm{k} 10 * \mathrm{k} 13 * \mathrm{k} 8 * *_{2}\right)$

$\mathrm{a} 3=(\mathrm{k} 12+\mathrm{k} 13) /(\mathrm{k} 8 * \mathrm{k} 11+\mathrm{k} 9 * \mathrm{k} 12 * \mathrm{k} 11 * * 2+\mathrm{k} 10 * \mathrm{k} 13 * k 8 * * 2)$

coeff $(1)=\mathrm{a} 3$

coeff $(2)=a 2$

coeff $(3)=a 1$

coeff $(4)=1$.

call ZPLRC (3, COEFF, zero)

write $(*, *)$ zero(1)

write $(*, *)$ zero(2)

write $(*, *)$ zero(3)

dJ1=real (zero (1))

dJ2 =real (zero (2))

dJ3 =real (zero (3))

$\operatorname{dum} 1=F(\alpha J 1)$

$\operatorname{dum} 2=F\left(a^{2} 2\right)$

$\operatorname{dum} 3=\mathrm{F}(\mathrm{dJ} 3)$ 
c write $(*, 600)$ dJ1, dJ2, aJ3, dum1, dum2, dum3

c600 format $(1 \mathrm{x}, 6 \mathrm{~d} 12.4)$

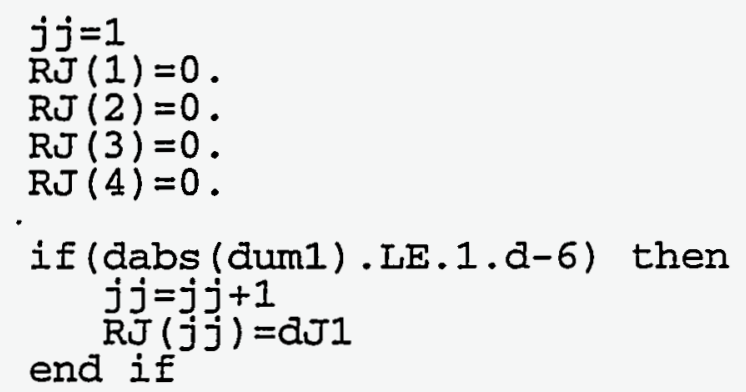

if (dabs (dum2) . LE.1.d-6) then $j j=j j+1$

end if

$R J(j j)=d J 2$

if (dabs (dum3) .LE.1.d-6) then

$j j=j j+1$

end if

c write(*.*) jj.

if $(j j . E Q .2)$ then

end if

$J t(k)=R J(2)$

if (jj.EQ.3) then

if(RJ $(2)$. GE.0.) then

else $J t(k)=R J(3)$

if (RJ (3).GE.0.) then

else $J t(k)=R J(2)$

C write (*,710) k, RJ (2), RJ (3) 710 format $\left(1 \times, x^{\prime} j j=3\right.$ and $R J(2) \&$ \&J $(3)$ are negative at $k={ }^{\prime}, i 3$,

$$
\text { if(RJ (2).LT.RJ (3)) then }
$$

else $J t(k)=R J(3)$

end if

end if

end if

end if

if (jj.EQ.4) then

c write (*,715) k, RJ (2), RJ (3), RJ (4)

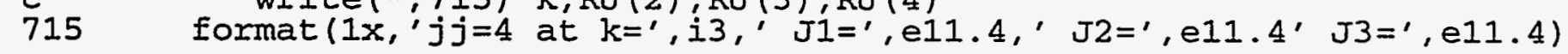

if(RJ (2).GT.RJ(3) .and. RJ(2).GT.RJ(4)) then

highi=RJ (2)

if (RJ (3).GT.RJ (4)) then

high2 $=R J(3)$

else high3 $=\mathrm{RJ}(4)$

high2=RJ (4) end if

high $3=R J(3)$

end if

if (RJ (3) .GT.RJ (2) .and. $R J(3)$. GT.RJ (4)) then 


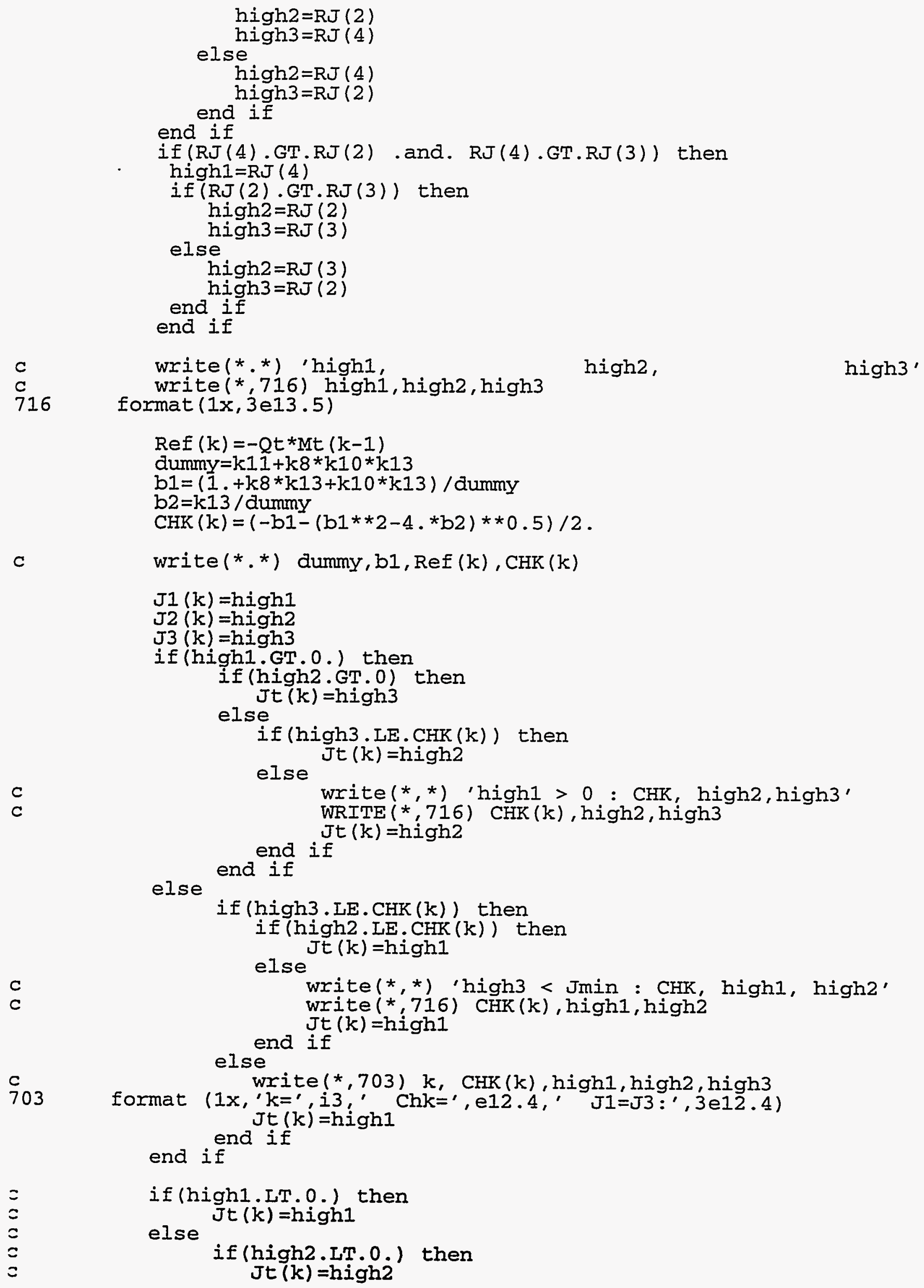

write $(* * *)$ 'high1,
write (*,716) high1, high2, high3

write (*, 703) k, CHK (k), high1, high2, high3

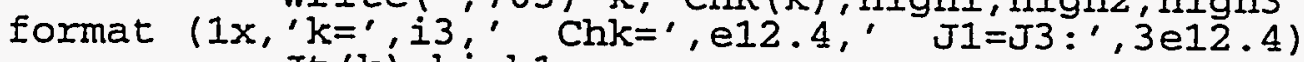

end if end if

if (high1.LT.0.) then

else Jt $(k)=h i g h 1$

if (high2.LT.0.) then

Jt $(\mathrm{k})=\mathrm{high} 2$ 
end if

$$
\begin{aligned}
& \text { else } \\
& \text { Jt }(k)=h i g h 3 \\
& \text { end if }
\end{aligned}
$$

end if

$$
\text { c } \quad \text { write }(*, *) \text { Jt }(k)
$$

$\mathrm{C}-$

Calculate variables at $z=z$

$$
\begin{aligned}
& \text { Os }(k)=O s(k-1)-2 . * J t(k) / Q s \\
& \operatorname{Osm}(k)=0 s(k)+2 . * J t(k) \quad / k 2 \\
& \mathrm{Cs}(\mathrm{k})=\mathrm{Cs}(\mathrm{k}-1)+\mathrm{Jt}(\mathrm{k}) / \mathrm{Qs} \\
& \operatorname{Csm}(k)=\operatorname{Cs}(k)-J t(k) / k 3 \\
& \operatorname{Otm}(k)=\operatorname{Osm}(k)+2 . * \mathrm{Jt}(\mathrm{k}) \quad / \mathrm{k} 4 \\
& \operatorname{Csm}(\mathrm{k})=\operatorname{Csm}(\mathrm{k}) \quad-\mathrm{Jt}(\mathrm{k}) \quad / \mathrm{k} 5
\end{aligned}
$$

$\operatorname{Ht}(\mathrm{k})=\mathrm{Ht}(\mathrm{k}-1)-2 . * \mathrm{Jt}(\mathrm{k}) / \mathrm{Qt}$
$\mathrm{Htm}(\mathrm{k})=\mathrm{Ht}(\mathrm{k})-2 . * \mathrm{Jt}(\mathrm{k})$
$\operatorname{Mt}(\mathrm{k})=\operatorname{Mt}(\mathrm{k}-1)+\mathrm{Jt}(\mathrm{k}) / \mathrm{Qt}$
$\operatorname{Mtm}(\mathrm{k})=\operatorname{Mt}(\mathrm{k})+\mathrm{Jt}(\mathrm{k})+\mathrm{k} 6$

alfa $(\mathrm{k})=\operatorname{Otm}(\mathrm{k}) / \mathrm{Htm}(\mathrm{k})$

$\operatorname{Rrex}(k)=1 . /($ alfa $(k) *$ ke)

$\operatorname{Rshe}(\mathrm{k})=\mathrm{Ri} /(\mathrm{Ro} * \mathrm{Keq} * a l f a(k) * * 2 * \mathrm{ksC})$

Rmem $(\mathrm{k})=\mathrm{Ri} /(\mathrm{RIm} * \mathrm{Keq} * a \operatorname{lfa}(\mathrm{k}) * * 2 * \mathrm{kmC})$

$\operatorname{Rtub}(\mathrm{k})=1 . / \mathrm{ktM}(\mathrm{k})$

$\mathrm{RW}(\mathrm{k})=\mathrm{Rrex}(\mathrm{k})+\mathrm{Rshe}(\mathrm{k})+\mathrm{Rmem}(\mathrm{k})+\mathrm{Rtub}(\mathrm{k})$

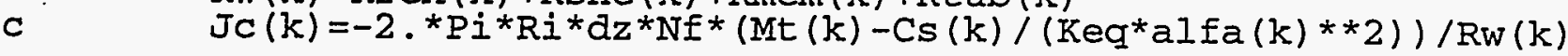

$\operatorname{dumj} 1(k)=-\operatorname{Cs}(k-1) /((k 3+k 5) /(k 3 * k 5)+k 9 * C s(k-1))$

dumj $2(\mathrm{k})=-1 \cdot / \mathrm{k} 8$

$\operatorname{dumj} 3(k)=-1 / k 10$

dumj $4(k)=-H t(k-1) /(2 . / k 7+k 11)$

Co the next increament

$\mathrm{y}=\mathrm{Mt}(\mathrm{nz}+1)-\mathrm{Mtout}$

yy=mtout

Remove $=100 . *($ Mtin-Mt $(n z+1)) /$ Mtin

error $=1$. - Mt $(n z+1) /$ Mtout

write $(*, 720)$ iter, $Q t$, Remove, $M t(n z+1)$, error

C write $(*, 720)$ iter, Qs, Remove, Mt $(n z+1)$, error

if (dabs (error) . IT. 1.d-6) go to 900

if (iter.GE.2) then

if $(x-y . E Q$. 0.$)$ then write $(* *)$ 'error for Total Mass Balance $=0$ ' end if go to 900

else

$$
\text { Mtout }=x *(y y-x x) /(x-y)+x x
$$

end if

$$
\text { Mtout }=\text { Mtout }+0.01 *(\text { Mt }(n z+1)-\text { Mtout })
$$

if(iter.EQ.1000) then

end if

write $\left({ }^{*},{ }^{*}\right)$ 'Total mass balance does not converge.' go to 900 


$$
\begin{aligned}
& x=y \\
& x x=y y \\
& \text { iter=iter } 1 \\
& \text { go to } 90
\end{aligned}
$$

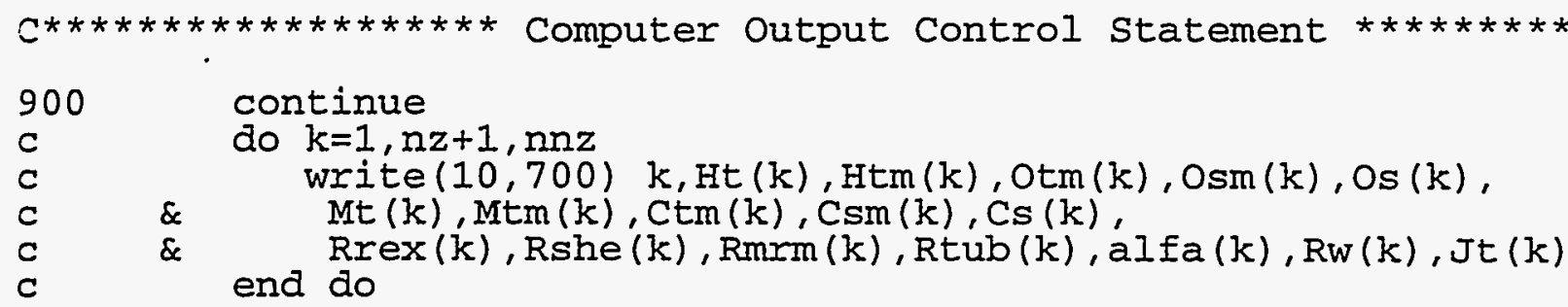

ExitCt $=\mathrm{Mt}(\mathrm{nz}+1) * 63.55 * 1000000$. write $(10,730)$ Qt, ExitCt, Remove write $(11,740)$ Qt, aktH, aktM, ExitCt, Remove

write $(12,750)$ Qt, aRw, aRrex, aRshe, aRmem, aRtub, aalfa

write $(10,735)$ Qs, Exitct, Remove

write $(11,740)$ Qs, kso, ksC, ExitCt, Remove

write $(12,750)$ Qs, aRw, aRrex, aRshe, aRmem, aRtub, aalfa

do $\mathrm{k}=1, \mathrm{nz}+1, \mathrm{nnz}$

write $(13,760)$ Qt, Jt (k), Jc (K)

format $(5 \mathrm{x}, \mathrm{f8} .4,2 \mathrm{e} 14.5)$

ExMt $=M t(k) * 63.55 * 1000000$.

write $(13,701) k, \operatorname{ref}(k), \operatorname{chk}(k), J 1(k), J 2(k), J 3(k), \operatorname{ExMt}$ end do

write $(13,701)$ Qt, (k, Jt (k), dumj1 (k), dumj2(k), dumj3(k),

format $\left(3 \mathrm{x},{ }^{\prime} \mathrm{Qt}={ }^{\prime}, \mathrm{f} 8.5 / 6(5 \mathrm{x}, \mathrm{i} 3,5 \mathrm{e} 12.4 /)\right)$ 


$$
\begin{aligned}
& \text { C-10 }
\end{aligned}
$$

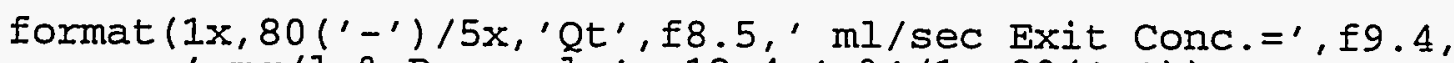

$$
\begin{aligned}
& \text { \&. ' } \mathrm{mg} / 1 \text { \& Removal=', e12.4,' } 8 \text { ' } / 1 \mathrm{x}, 80\left(^{\prime}{ }^{\prime}\right) \text { ) } \\
& \text { format }\left(1 \mathrm{x}, 80\left(^{\prime} \mathrm{-}^{\prime}\right) / 5 \mathrm{x}, ' \mathrm{Qs}=', \mathrm{f8} .5^{\prime} \mathrm{ml} / \mathrm{sec}\right. \text { Exit Conc.=', f9.4, }
\end{aligned}
$$

